\title{
Theoretical Study on Vibration Control of Symmetric Structure with Shape Memory Alloy (SMA)-Friction Damper
}

\author{
Yunli Gao ${ }^{1}$ and Wenjie Ren ${ }^{*}, 2$ \\ ${ }^{1}$ Department of Civil Engineering and Architecture, Dalian Nationalities University, Dalian, Liaoning, 116600, China \\ ${ }^{2}$ College of Civil Engineering, Hebei University of Technology, Tianjin, 300401, China
}

\begin{abstract}
The paper proposed an innovative shape memory alloy (SMA)-friction damper. The damper consisted of the superelastic SMA wire and the friction element in series. According to the working mechanism of the damper, the paper set up the mechanical model of the damper. Seismic elastic-plastic time history response analysis program and energy analysis program of the damped structure were designed. The numerical calculations of the vibration control of a threestory shear-type symmetric structure with the damper were carried out. The results indicated that the damper can decrease the displacement and the inter-story displacement of the structure effectively, but increase the acceleration of the structure comparing with uncontrolled structure. The SMA-friction damper can not only adjust the working status of the energy dissipation elements automatically according to the seismic responses of the structure, but also has some advantages as simple configuration and economical application.
\end{abstract}

Keywords: Mechanical model, Shape memory alloy-friction damper, Symmetric structure, Vibration control.

\section{INTRODUCTION}

Shape memory alloy (SMA) is an innovative material. It shows a large reversible strain due to superelasticity. In particular, the Ni-Ti-based alloy exhibits some ductility and excellent superelastic strain. SMA is used in electronics, machinery, energy, medical, aerospace and automotive industry at present. Since the 90's of the last century, SMA began to be used in the field of civil engineering as an intelligent material. Its application has continuously increased, especially the use of SMA superelastic dampers on the passive vibration control structure has attracted the attention of the scholars. For example, Zhu and Zhang [1] presented a special type of bracing element termed as reusable hysteretic damping brace (RHDB), and studied the seismic behaviour of a concentrically braced frame system with self-centering capability. Li et al. [2] proposed two types of shape memory alloy (SMA)-based devices; the tension-SMA device (TSD) and the scissor-SMA device (SSD). Parulekar et al. [3] designed and fabricated a damper device. Taking into account the residual martensite accumulation irreversibly due to cyclic forward reverse martensitic transformation, a study was conducted using a thermo-mechanical model of SMA. Asgarian and Moradi [4] investigated the seismic performance of steel frames equipped with superelastic SMA braces. Buildings with different bracing configurations including diagonal, split $\mathrm{X}$, chevron ( $\mathrm{V}$ and inverted $\mathrm{V}$ ) bracings were considered. Di Cesare and Ponzo [5] referred to the experimental tests based on the model equipped with two different systems based

*Address correspondence to this author at the College of Civil Engineering, Hebei University of Technology, Tianjin, 300401, P.R. China;

Tel: +86(13662139163); E-mail: renwenj0406@163.com on Hysteretic Dampers (HD) and visco-re-centering devices $(\mathrm{SMA}+\mathrm{VD})$. The devices could restrict the inter-story drifts, and the frame yielding was surely prevented. Osman and Stefan [6] proposed a new re-centering variable friction device (RVFD), to investigate the seismic response control of a 20-story nonlinear benchmark building. The energy dissipation capabilities of a variable friction damper (VFD) and the re-centering ability of shape memory alloy (SMA) wires were observed in the RVFD.

The experiments and theories proved that these SMA dampers can effectively limit the seismic response of the structure and ensure the safety of structure. But some problems could not be resolved in the past research. Energy dissipation element of damper (SMA or SMA and other energy dissipation materials) acts on the structure at the same time, and these dampers cannot automatically adjust the energy dissipation according to seismic response of the structure. The quantities of SMA wires are determined according to seismic responses of the structure under strong earthquake which requires a lot of SMA wires. But the abilities of SMA dampers are not fully released under small earthquake or moderate earthquake. It is not economic because the SMA wires are expensive.

The paper proposed an innovative shape memory alloy (SMA)-friction damper. Consisting of the superelastic SMA wire and the friction element in series, the damper can not only adjust the working status of the energy dissipation elements automatically according to the seismic responses of the structure, but also has simple configuration and economical application. According to the working mechanism of the damper, the mechanical model was established. Seismic elastic-plastic time history response analysis program and energy analysis program of the damped structure were designed. The numerical calculations 
on vibration control of a three-story shear-type symmetric structure with the damper were carried out.

\section{STRUCTURE AND WORKING MECHANISM OF SHAPE MEMORY ALLOY (SMA)-FRICTION DAMPER}

\subsection{Structure of SMA-Friction Damper}

The structure of shape memory alloy (SMA)-friction damper is shown in Fig. (1). The damper consists of first level board (1), front side board (2), right moving rod (3), super elastic SMA wire (4), left moving rod (5), friction plate (6), second level board (7), back side board (8), high strength bolt (9), wire wrapped implement (10), fixed screw (11), connecting bolt (12), sleeve (13), fixture (14) and PTFE sheet (15). Numbers in brackets correspond to the each element of the damper shown in Fig. (1) [7].

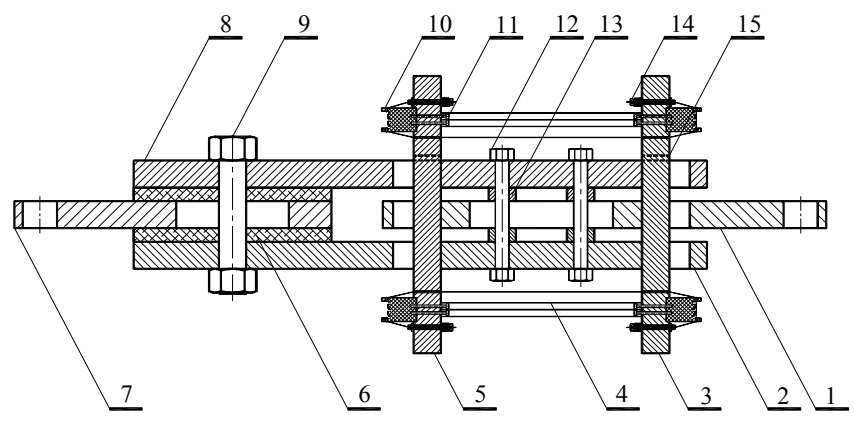

Fig. (1). Schematic sketch of SMA-friction damper.

\subsection{Working Mechanism of SMA-Friction Damper}

The damper can adjust the working status of energy dissipation elements automatically when sliding friction force of the damper is more than the maximum restoring force of the SMA wires. The working mechanism of the damper under pullout load is described as.

1) On the small load, the displacement of first level board is less than second level board. The first level board drives the right moving rod moving, and the left moving rod is stopped by the front side board and the back side board. The SMA wires are stretched. While unloading load, the right moving rod and first level board are reset by the restoring force of the SMA wires. Less energy is consumed in the process of stretching or retracting the SMA wires.

2) On the big load, the displacement of first level board is more than the second level board. The left moving rod and right moving rod approach to contact the first level board, the front side board and back side board. If the contact force is more than the maximum static friction force of the damper, the front side board and back side board which are stuck on friction sheet have relative sliding displacements to the second level board. The friction force is produced and a lot of energy is consumed. Meanwhile, the SMA wires keep the maximum stretch length and their abilities are fully released. While unloading load, the stretch length is reset and the friction sliding length shows residual displacement.

\section{MECHANICAL MODEL OF SMA-FRICTION DAMPER}

\subsection{Graesser's Constitutive Equations of the Superelastic} SMA

Graesser's constitutive equations [8] are used to describe the stress $\sigma$-strain $\varepsilon$ relationship of the SMA wires. The formulas are:

$$
\begin{aligned}
& \dot{\sigma}=E \times\left[\dot{\varepsilon}-|\dot{\varepsilon}|\left(\frac{\sigma-\beta}{Y}\right)^{n}\right] \\
& \beta=E \times \alpha \times\left\{\varepsilon-\frac{\sigma}{E}+f_{\mathrm{T}}|\varepsilon|^{c} \operatorname{erf}(a \varepsilon)[\mathrm{u}(-\varepsilon \dot{\varepsilon})]\right\}
\end{aligned}
$$

where $E$ is elastic modulus, $Y$ is yielding stress, $\alpha=E^{\prime} /\left(E-E^{\prime}\right), E^{\prime}$ is the slope of $\sigma-\varepsilon$ curve as SMA wire yielding, $n, f_{\mathrm{T}}, a, c$ are constants related to the materials, $\operatorname{erf}()$ and $\mathrm{u}()$ are the error function and the unit step function, respectively. The expressions are:

$$
\begin{aligned}
& \operatorname{erf}(y)=\frac{2}{\sqrt{\pi}} \int_{0}^{y} e^{-t^{2}} d t \\
& \mathrm{u}(y)= \begin{cases}1 & (y \geq 0) \\
0 & (y<0)\end{cases}
\end{aligned}
$$

\subsection{Mechanical Model of SMA-Friction Damper}

According to the working mechanism of the damper, the restoring force can be written as:

$f_{\mathrm{d}}=\left\{\begin{array}{cc}f_{\mathrm{SMA}} & \left(x_{\text {min }}^{\prime}<x_{\mathrm{d}}<x_{\text {max }}^{\prime}\right) \\ f_{\mathrm{FRI}} & \left(x_{\mathrm{d}} \geq x_{\text {max }}^{\prime}\right) \\ -f_{\mathrm{FRI}} & \left(x_{\mathrm{d}} \leq x_{\text {min }}^{\prime}\right)\end{array}\right.$

where $x_{\mathrm{d}}$ and $f_{\mathrm{d}}$ are respectively displacement and restoring force of the damper, and $x_{\max }^{\prime}$ and $x_{\min }^{\prime}$ are critical displacements. As the residual displacement of the damper becomes equal to zero, $x_{\max }^{\prime}=-x_{\min }^{\prime}=x_{\mathrm{e}}$, where $x_{\mathrm{e}}$ is the maximum stretch length of the single SMA wire. As the residual displacement of the damper is not equal to zero, $x_{\max }^{\prime}$ and $x_{\min }^{\prime}$ are corresponding displacements when the tensile load and pressure load begin to be unloaded, satisfying $x_{\text {max }}^{\prime}-x_{\text {min }}^{\prime}=2 x_{\mathrm{e}} \cdot f_{\mathrm{FRI}}$ is the sliding friction force, and $f_{\text {SMA }}$ is the restoring force of the SMA wires, $f_{\mathrm{SMA}}=\sigma \times A$, where $A$ is the total cross-sectional area of SMA wires.

\section{VIBRATION ANALYSIS OF SYMMETRIC DAMPED STRUCTURE}

Seismic elastic-plastic time history response analysis program and energy analysis program of the damped structure were designed by Matlab. 


\subsection{Motion Equations of Symmetric Damped Structure}

A p-story shear-type symmetric structure with the damper was studied, as shown in Fig. (2). The hypotheses are given below:

1) The slab is infinitely rigid in its own plane.

2) The quality of all the members of the structure piles up on the slab is based on the proximity principle.

3) Bottom structure and foundation are perfectly fixed, and joint action of upper structure and foundation is not considered.

4) The damper and brace in series are installed on the structure, and with the stiffness of brace being infinity.

The structure generates elastic-plastic deformation under intense earthquake. The inter-story restoring forces are computed according to the Bouc-Wen model [9]:

$$
\begin{aligned}
& f_{\mathrm{s}}=\delta k_{\mathrm{e}} x_{\mathrm{c}}+(1-\delta) k_{\mathrm{e}} x_{\mathrm{cy}} z \\
& \dot{z}=\frac{1}{x_{\mathrm{cy}}}\left[\lambda \dot{x}_{\mathrm{c}}-\mu\left|\dot{x}_{\mathrm{c}}\right||z|^{\eta-1} z-\gamma \dot{x}_{\mathrm{c}}|z|^{\eta}\right]
\end{aligned}
$$

where $k_{\mathrm{e}}$ is the inter-story initial elastic stiffness of the structure, $\delta$ is the ratio of inter-story yielding stiffness to the initial elastic stiffness, $x_{\mathrm{c}}$ is the inter-story displacement, $x_{\text {cy }}$ is the inter-story yielding displacement, and $\lambda, \mu, \gamma$ and $\eta$ are parameters that control the shape and smoothness of $f_{\mathrm{s}}-x_{\mathrm{cy}}$ curve.

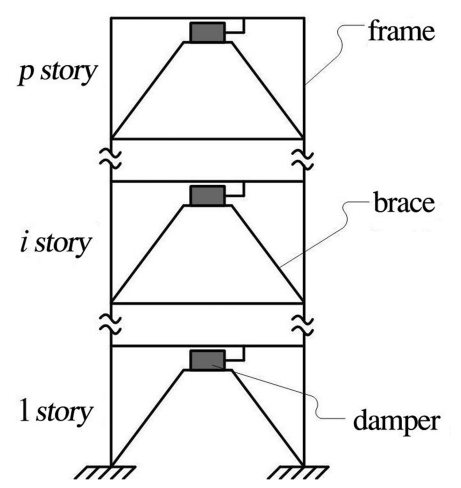

Fig. (2). Model of structure.

The equations of motion of damped structure are written as:

$$
\boldsymbol{M}_{\mathrm{s}} \ddot{\boldsymbol{X}}(t)+\boldsymbol{C}_{\mathrm{s}} \dot{\boldsymbol{X}}(t)+\boldsymbol{H F}_{\mathbf{s}}(t)+\boldsymbol{H F}_{\mathrm{d}}(t)=-\boldsymbol{M}_{\mathrm{s}} \boldsymbol{I}_{\mathrm{g}}(t)
$$

where $\boldsymbol{X}(t), \dot{\boldsymbol{X}}(t)$ and $\ddot{\boldsymbol{X}}(t)$ are column vector of the displacement, column vector of the speed and column vector of the acceleration, respectively; $\ddot{x}_{\mathrm{g}}(t)$ is ground acceleration; $\boldsymbol{I}$ is $p$ dimensional 1 column vector; $\boldsymbol{M}_{\mathbf{s}}$ is the mass matrix of structure; $\boldsymbol{C}$ is Rayleigh damping matrix; $\boldsymbol{C}=a_{1} \boldsymbol{M}_{\mathrm{s}}+a_{2} \boldsymbol{K}_{\mathrm{se}}, \boldsymbol{K}_{\mathrm{se}}$ is the initial elastic stiffness matrix of structure; $a_{1}$ and $a_{2}$ are coefficients that are calculated according to the ratio of the preceding two mode shapes damping $\xi_{1}$ to $\xi_{2} ; \boldsymbol{F}_{\mathbf{s}}(t)$ is column vector of the inter-story restoring force; and $\boldsymbol{F}_{\mathbf{d}}(t)$ is column vector of the damper restoring force. If the $i$ story has no damper, the $i$ line of $\boldsymbol{F}_{\mathbf{d}}(t)$ equals 0 , and $\boldsymbol{H}$ is represented as $p \times p$ matrix, its expression is as follows:

$$
\boldsymbol{H}=\left[\begin{array}{ccccc}
1 & -1 & 0 & \cdots & 0 \\
0 & 1 & -1 & \ddots & \vdots \\
0 & \ddots & \ddots & \ddots & 0 \\
\vdots & \ddots & 0 & 1 & -1 \\
0 & \cdots & 0 & 0 & 1
\end{array}\right]
$$

\subsection{Energy Balance Equation of Damped Structure}

Each component in the formula (8) integrates with the relative displacement, and the energy balance equation of structure can be given as [10]:

$E_{\mathrm{k}}(t)+E_{\mathrm{c}}(t)+E_{\mathrm{s}}(t)+E_{\mathrm{d}}(t)=E_{\mathrm{in}}(t)$

where $E_{\mathrm{k}}(t)$ is the structural kinetic energy, $E_{\mathrm{k}}=\frac{1}{2} \dot{\boldsymbol{X}}(t)^{\mathrm{T}} \boldsymbol{M}_{\mathrm{s}} \dot{\boldsymbol{X}}(t) . E_{\mathrm{c}}(t)$ is the structural internal damping energy, $E_{\mathrm{c}}=\int \dot{\boldsymbol{X}}(t)^{\mathrm{T}} \boldsymbol{C}_{\mathrm{s}} \dot{\boldsymbol{X}}(t) d t . E_{\mathrm{s}}(t)$ is the structural strain energy, $E_{\mathrm{s}}=\int\left[\boldsymbol{H F}_{\mathrm{s}}(t)\right]^{\mathrm{T}} \dot{\boldsymbol{X}}(t) d t$, which includes hysteretic dissipation energy and elastic strain energy. When the structure tends to be static after earthquake, elastic strain energy will approach $0 . E_{\mathrm{d}}(t)$ is the dissipation energy of the damper, $E_{\mathrm{d}}=\int\left[\boldsymbol{H F}_{\mathbf{d}}(t)\right]^{\mathrm{T}} \dot{\boldsymbol{X}}(t) d t, E_{\text {in }}(t)$ is the total input energy of the structure when the earthquake occurred $E_{\mathrm{in}}=\int\left[-\boldsymbol{M}_{\mathrm{s}} \boldsymbol{I} \ddot{x}_{\mathrm{g}}(t)\right]^{\mathrm{T}} \dot{\boldsymbol{X}}(t) d t$.

\section{VIBRATION CONTROL CALCULATION OF SYMMETRIC STRUCTURE WITH SMA-FRICTION DAMPER}

\subsection{Model Introduction}

The three-story shear-type symmetric structure was studied in this paper. The quality of each story was $m=1 \times 10^{5} \mathrm{~kg}$. The inter-story restoring force model parameters of each story are as follows:

$k_{\mathrm{e}}=5 \times 10^{7} \mathrm{~N} / \mathrm{m}, \delta=0.3, \lambda=1, \mu=0.9, \gamma=0.1, \eta=95$, of the first story, the second story included $x_{\text {cy }}=0.014 \mathrm{~m}$ and the third story had $x_{\mathrm{cy}}=0.010 \mathrm{~m}$, with $\xi_{1}=\xi_{2}=0.05$. The self-vibration periods of the structure which were calculated were $0.631 \mathrm{~s}, 0.225 \mathrm{~s}$ and $0.156 \mathrm{~s}$, respectively.

The mechanical model parameters of the SMA-friction damper are as follows: $A=55.292 \mathrm{~mm}^{2}, E=3402.7 \mathrm{GPa}$, $Y=47.85 \mathrm{GPa}, \alpha=0.13, n=5, f_{\mathrm{T}}=0.23, a=197$, $c=0.09, f_{\mathrm{FRI}}=75.9 \mathrm{kN}$, and $x_{\mathrm{e}}=12 \mathrm{~mm}$. The length of the single SMA wire was $200 \mathrm{~mm}$. 
Table 1. Peak Response and Reduction Ratio of Structure.

\begin{tabular}{|c|c|c|c|c|c|c|c|c|c|}
\hline \multirow{2}{*}{ Story } & \multicolumn{3}{|c|}{$x_{\max } / \mathrm{mm}$} & \multicolumn{3}{c|}{$x_{\mathrm{cmax}} / \mathrm{mm}$} & \multicolumn{2}{c|}{$\ddot{x}_{\max } / \mathrm{m} / \mathrm{s}^{2}$} \\
\cline { 2 - 10 } & $\begin{array}{c}\text { Uncontrolled } \\
\text { Structure }\end{array}$ & $\begin{array}{c}\text { Damped } \\
\text { Structure }\end{array}$ & $\begin{array}{c}\text { Reduction } \\
\text { Ratio }\end{array}$ & $\begin{array}{c}\text { Uncontrolled } \\
\text { Structure }\end{array}$ & $\begin{array}{c}\text { Damped } \\
\text { Structure }\end{array}$ & $\begin{array}{c}\text { Reduction } \\
\text { Ratio }\end{array}$ & $\begin{array}{c}\text { Uncontrolled } \\
\text { Structure }\end{array}$ & $\begin{array}{c}\text { Damped } \\
\text { Structure }\end{array}$ & $\begin{array}{c}\text { Reduction } \\
\text { Ratio }\end{array}$ \\
\hline \hline 1 & 41.23 & 22.71 & $44.92 \%$ & 41.23 & 22.71 & $44.92 \%$ & 5.27 & 8.06 & $-52.94 \%$ \\
\hline 2 & 68.76 & 41.65 & $39.43 \%$ & 27.86 & 18.93 & $32.05 \%$ & 6.13 & 8.34 & $-36.05 \%$ \\
\hline 3 & 77.98 & 49.39 & $36.66 \%$ & 12.25 & 10.02 & $18.20 \%$ & 8.53 & 9.15 & $-7.27 \%$ \\
\hline
\end{tabular}

The dampers installed on the structure are shown in Fig. (2). In order to limit the vibration of each story, the quantities of damper were determined in which 11 were in the first story, 7 in the second story, and 11 in the third story.

El-Centro wave (1940.5.18) was selected as seismic dynamic recording. The intense earthquake with time duration $t=0 \mathrm{~s} \sim 10 \mathrm{~s}$ was selected. The peak acceleration was adjusted to $4 \mathrm{~m} / \mathrm{s}^{2}$. In order to evaluate the restoring function of damper, the structure was allowed to freely vibrate $10 \mathrm{~s}$ after the earthquake's wave stopped.

\subsection{Calculation Results and Analysis}

The peak displacement $x_{\max }$, the peak inter-story displacement $x_{\text {cmax }}$, the peak acceleration $\ddot{x}_{\max }$ and reduction ratio are shown in Table 1 . The inter-story displacement time history curves of structure are shown in Fig. (3). The displacement and inter-story displacement of structure can be restricted by damper, and reduction ratios were observed to be $44.92 \% \sim 36.66 \%$ and $44.92 \% \sim 18.20 \%$. The acceleration of structure was increased from $52.94 \%$ $7.27 \%$ because the dampers create additional structural stiffness. Compared with uncontrolled structure, residual displacement of the first story and second story increased and their value were $6.31 \mathrm{~mm}$ and $2.53 \mathrm{~mm}$ in damped structure, respectively. Residual displacement of third story decreases and approximates to 0 .

To understand the elastic-plastic hysteretic behavior and the mechanism of damper, inter-story force-displacement curves of damped structure are shown as Fig. (4), the forcedisplacement curves of SMA-friction damper of the damped structure are shown as Fig. (5), and the energy time and history curves of damped structure and uncontrolled structure are shown in Fig. (6).

1) The first story and the second story were on the elastic-plastic stage, and the third story was kept on the elastic stage as shown in Fig. (4).

2) In Fig. (5), the SMA wires and friction element of the first story and the second story damper acted on the structure in sequence. The hysteretic loop was completed and the energy dissipation was observed as high. The result indicates that the vibration of structure was controlled but residual displacement was observed after the earthquake. Only the SMA wires of the third story damper acted on the structure, and the hysteretic loop was narrow with low energy dissipation. Therefore, the reduction ratio was smaller but it showed an excellent self-centering capacity.

(a) First Story

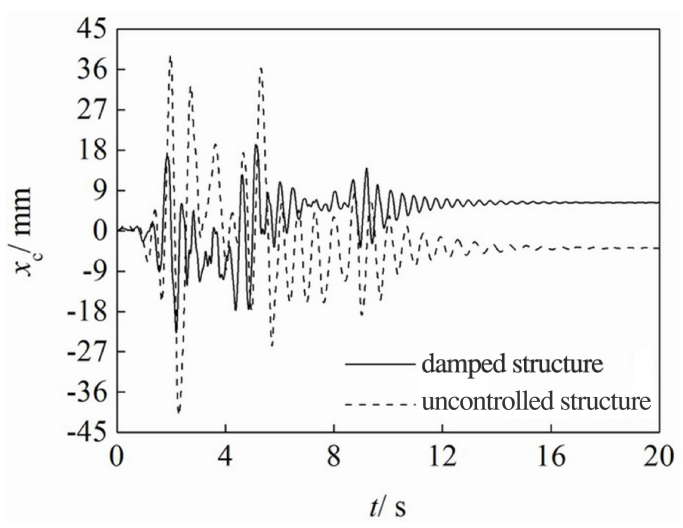

(b) Second Story

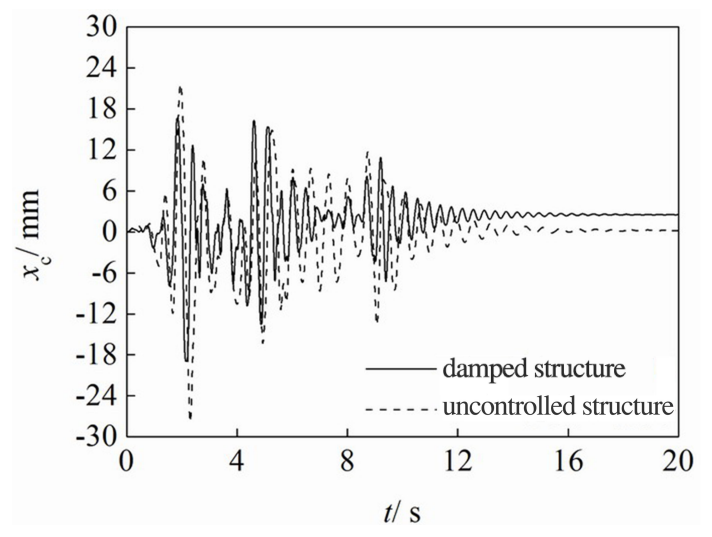

(c) Third Story

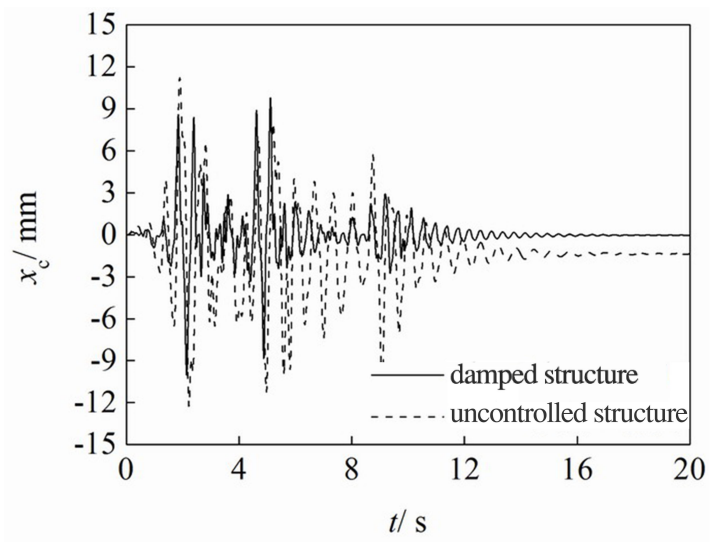

Fig. (3). Inter-story displacement time history of structure. 
3) In Fig. (6), the input energy of damped structure ( $\left.E_{\mathrm{i}}=167.46 \mathrm{~kJ}\right)$ decreased $25.03 \%$ than the uncontrolled structure $\left(E_{\mathrm{i}}=223.36 \mathrm{~kJ}\right)$ because the structure vibration was restricted by damper. In the uncontrolled structure, the structure consumed total input energy ( $\left.E_{\mathrm{s}}=130.21 \mathrm{~kJ}, E_{\mathrm{c}}=93.15 \mathrm{~kJ}\right)$ because of its hysteresis behavior and internal damping. In the damped structure, $50.46 \%$ input energy $\left(E_{\mathrm{d}}=84.50 \mathrm{~kJ}\right)$ was consumed by damper, and hysteretic energy and internal damping energy were decreased ( $\left.E_{\mathrm{s}}=26.51 \mathrm{~kJ}, E_{\mathrm{c}}=56.45 \mathrm{~kJ}\right)$, and the safety of the structure was ensured.

(a) First Story

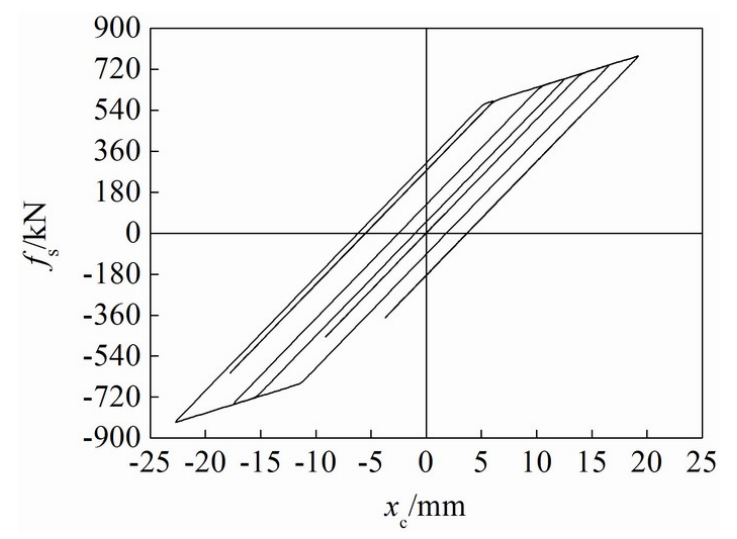

(b) Second Story

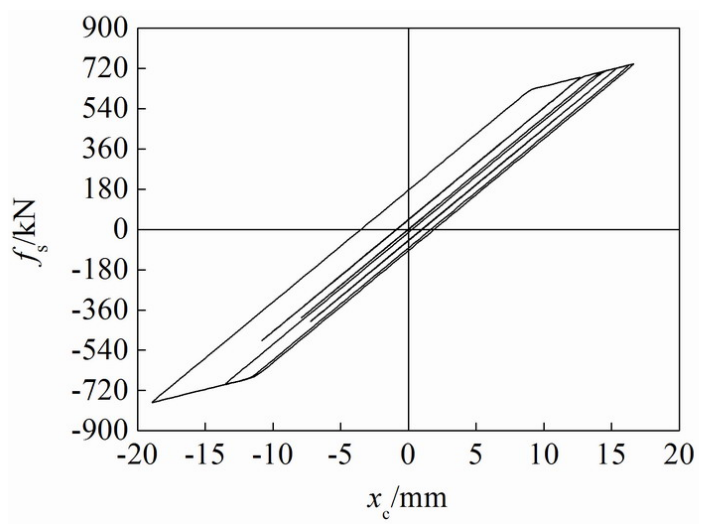

(c) Third Story

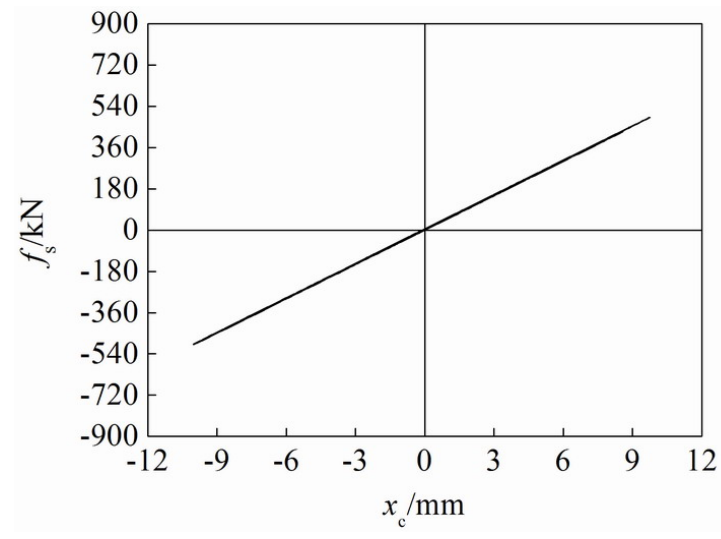

Fig. (4). Inter-story force-displacement curve of damped structure. (a) First Story

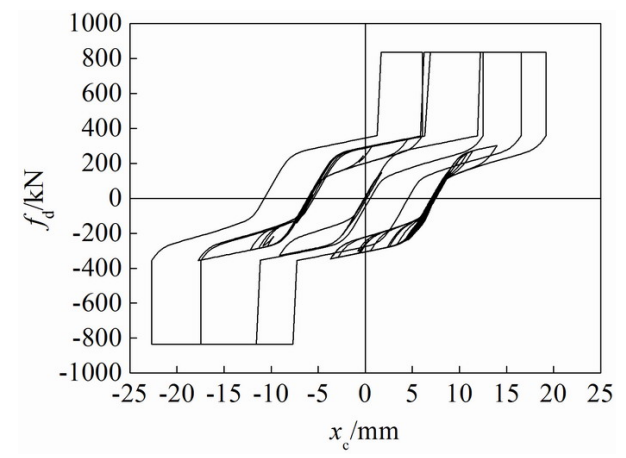

(b) Second Story

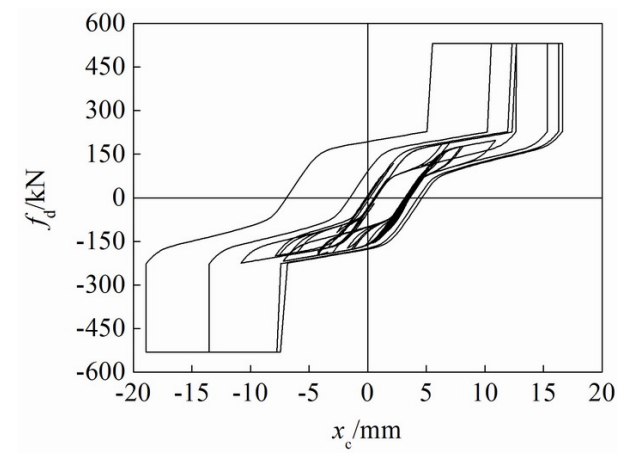

(c) Third Story

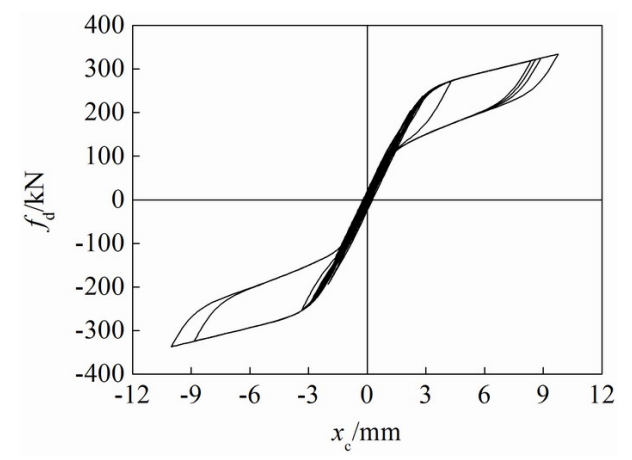

Fig. (5). Force-displacement curve of sma-friction damper on damped structure.

\section{CONCLUSION}

An innovative shape memory alloy (SMA)-friction damper was proposed in this study. Consisting of the superelastic SMA wires and the friction element in series, the damper can adjust the working status of the energy dissipation elements automatically according to the seismic responses of the structure. Only SMA wires worked under small load, and the SMA wires and friction element functioned in sequence under large load. The configuration of damper is simple and economical. According to the working mechanism of damper, its mechanical model was also given. Seismic elastic-plastic time history response analysis program and energy analysis program of the damped structure were designed by Matlab. Studies on vibration control of a three-story shear-type symmetric structure with damper were carried out. The results indicated that the damper can effectively decrease the displacement and the inter-story displacement of the 
structure, but increase the acceleration of the structure. Furthermore, the SMA wires exhibit low energy dissipation but have an excellent self-centering capacity, and the friction element creates substantial energy but makes the structure manifest residual displacement after earthquake.

(a) Uncontrolled Structure

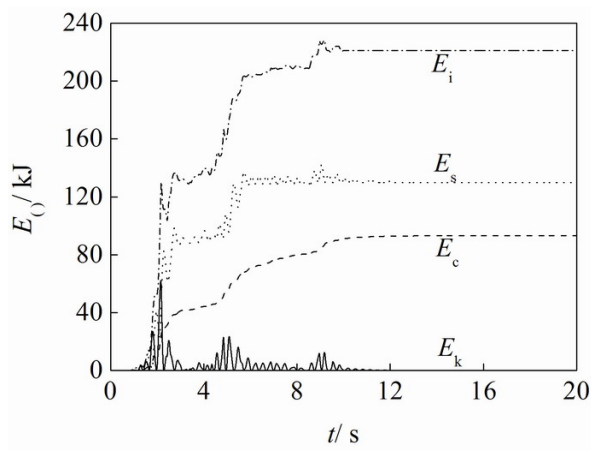

(b) Damped Structure

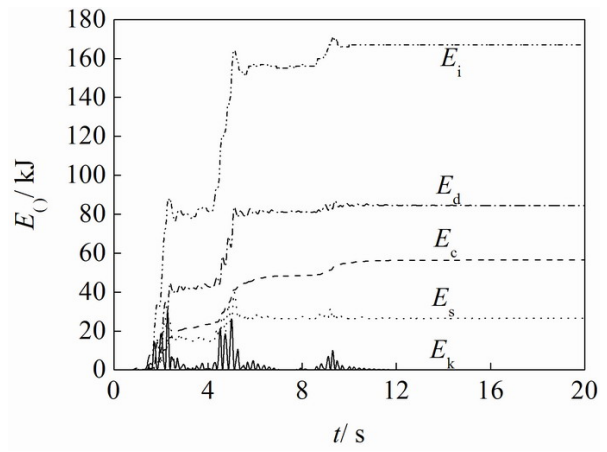

Fig. (6). Energy time history of structure.

\section{CONFLICT OF INTEREST}

The authors confirm that this article content has no conflict of interest.

\section{ACKNOWLEDGMENTS}

This work is supported by the General Program Foundation of NSFC (No.50978081), the Central Universities Independent Research Fund, China (No. DC201502040302).

\section{REFERENCES}

[1] S. Y. Zhu, and Y. F. Zhang, "Seismic behaviour of self-centring braced frame buildings with reusable hysteretic damping brace," Earthquake Engineering and Structural Dynamics, vol. 36, no. 10, pp. 1329-1346, 2007.

[2] H. Li, C. X. Mao, and J. P. Ou, "Experimental and theoretical study on two types of shape memory alloy devices," Earthquake engineering and structural dynamics, vol. 7, no. 3, pp. 407-426, 2008.

[3] Y. M. Parulekar, G. R. Reddy, K. K. Vaze, S. Guha, C. Gupta, and K. Muthumani, "Seismic response attenuation of structures using shape memory alloy dampers," Structural control and health monitoring, vol. 19, no. 1, pp. 102-119, 2010

[4] B. Asgarian, and S. Moradi, "Seismic response of steel braced frames with shape memory alloy braces," Journal of Constructional Steel Research, vol. 67, no. 1, pp. 65-74, 2011.

[5] C. A. Di, F. C. Ponzo, D. Nigro, and D. Moccia, "Dynamic tests on a steel frame equipped with hysteretic and visco-re-centring energy dissipating bracing systems," Procedia Engineering, vol. 14, pp. 2931-2940, 2011.

[6] O. E. Ozbulut, and H. Stefan, "Application of an SMA-based hybrid control device to 20-story nonlinear benchmark building," Earthquake engineering and structural dynamics, vol. 41, no. 7, pp. 1831-1843, 2012

[7] W. Ren, L. Wang, Z. Ma, and H. Yao, "Investigation on mechanical behavior of innovative shape memory alloy-friction damper," Journal of Building Structures, vol. 34, no. 2, 2013. (in Chinese)

[8] E. J. Graesser, and F. A. Cozzarelli, "Shape-memory alloys as new materials for aseismic isolation," Journal of Engineering Mechanics, vol. 117, no. 11, pp. 2590-2608, 1991

[9] L. M. Moreschi, and M. P. Singh, "Design of yielding metallic and friction dampers for optimal seismic performance," Earthquake Engineering and Structural Dynamics, vol. 32, no. 8, pp. 12911311, 2003.

[10] T. T. Soong, and G. F. Dargush, "Passive energy dissipation systems in structural engineering," Science Press: Beijing, 2005. (in Chinese). 